\title{
INEQUALITIES FOR FRACTIONAL DIFFERENTIAL EQUATIONS
}

\author{
K. M. FURATI AND N.-E. TATAR
}

Abstract. We consider some differential inequalities involving fractional derivatives in the sense of Riemann-Liouville. Bounds for theses fractional differential inequalities are found using desingularization techniques combined with some generalizations of Bihari-type inequalities. Some applications illustrating the usefulness of our results are also provided.

Mathematics subject classification (2000): 26D10, 26D15, 42B20.

Keywords and phrases: Bihari inequality, exponential decay, fractional derivative, fractional differential inequality, power type decay.

\section{REFERENCES}

1] G. A. AnASTASSIOU, Opial type inequalities involving fractional derivatives of functions, Nonlinear Studies, 6:207-230, 1999.

[2] G. A. Anastassiou, J. J. Koliha, And J. Pecaric, Opial inequalities for fractional derivatives, Dynamic Systems and Applications, 10:395-406, 2001.

[3] D. Bainov And P. SimEOnOv, Integral Inequalities and Applications, volume 57, Kluwer Acad. Publishers, Dordrecht, Boston, London, 1992.

[4] K. M. FURATI AND N. E. TATAR, An existence result for a nonlocal fractional differential problem, Journal of Fractional Calculus, 26:43-51, 2004.

[5] K. M. FURATI AND N. E. TATAR, Power-type estimates for a nonlinear fractional differential equation, Nonlinear Analysis: Theory, Methods \& Applications, 62(6):1025-1036, 2005.

[6] K. M. FURATI AND N. E. TATAR, Some fractional differential inequalities and their applications, Mathematical Inequalities and Applications, 9(4):577-598, 2006.

[7] K. M. FURATI AND N. TATAR, Behaviour of solutions for a weighted Cauchy-type fractional differential problem, Journal of Fractional Calculus, 28:23-42, 2005.

[8] A. A. Kilbas, H. M. Srivastava, And J. J. Trujillo, Theory and Applications of Fractional Differential Equations, volume 204 of Mathematics Studies, Elsevier, 2006.

[9] A. A. Kilbas And J. J. Trujillo, Differential equations of fractional order: methods, results and problems, I, Applicable Analysis, 78:153-192, 2001.

[10] A. A. Kilbas And J. J. TRujILlo, Differential equations of fractional order: methods, results and problems, II, Applicable Analysis, 81:435-493, 2002.

[11] B. G. PACHPATTE, Inequalities for Differential and Integral Equations, volume 197 of Mathematics in Science and Engineering, Acad. Press, San Diego-London, 1998. Edited by W. F. Ames.

[12] I. PodLuBny, Fractional Differential Equations, volume 198 of Mathematics in Science and Engineering, Acad. Press, 1999.

[13] S. G. Samko, A. A. Kilbas, And O. I. Marichev, Fractional Integrals and Derivatives, Theory and Applications, Gordon and Breach, Amsterdam, 1993. Engl. Trans. From the Russian 1987. 